\title{
The Physical Ability of the Assistant Referee in Decision Making in the Indonesian League
}

\author{
Mochamad Yamin Saputra*, Herman Subarjah, Komarudin Komarudin, Yusuf Hidayat \\ Sports Education \\ Universitas Pendidikan Indonesia \\ Bandung, Indonesia \\ *mochyamins@upi.edu
}

\begin{abstract}
The decision of the referee and assistant referee in football can be determined by several factors, one of which is the position when making a decision. When the assistant referee takes a decision, the ideal position is always at the same level as the last defender, with a view that must look at the position of the ball, the last defender and the attacking player who will touch the ball. The ideal position held by the assistant referee in a match is a reflection of the physical abilities possessed by the assistant referee. So the researcher has a desire to know the physical ability factor that is owned by the assistant football referee in the Indonesian League in making decisions. In this study the researcher used descriptive method with population using FIFA licensed referee assistant totaling 7 people and the sample used total sampling. The results of the authors observation obtained the physical ability of the assistant referee was in the very good category, and there was a significant influence with a correlation value of 0.887 . The conclusion of this study the physical ability of the assistant referee has a significant influence in the decision making of assistant referees in the Indonesian League.
\end{abstract}

Keywords—physical ability; decision making; referee

\section{INTRODUCTION}

Football is one of the most popular sports in the world [1], with this supercupler makes soccer sport has its own appeal to all elements of society, not only adults, children and even no gender differences in loving football. In soccer games there are many elements involved, players playing in the field, reserve players, coaches, managers, referees, health workers, media, sponsors and spectators [2]. All the elements involved are one and the other has their respective duties, in their duties with one another must have a feeling of mutual respect, so that the match can run in accordance with applicable rules [3]. In this study researchers only looked at the elements and the role of assistant referees in leading matches in Indonesian league 1.

Sports referees have a challenging job, because there are many aspects of the game / match that they have to take into account, the speed and complexity of the decisions they have to make, the impact of the referee's actions, the number of people involved in the match, and the spectator disputes in sports. They are required to perform various tasks, including evaluating and evaluating actions that occur during matches, making quick decisions, managing games, paying attention to many aspects of the game, maintaining order, and resolving disputes [4]. All of this not only makes the referee's work very complicated, but also makes it easy to make mistakes. As a consequence of the decisions taken by the referee, the referee must be prepared to be criticized for his decision [5]. This criticism may come from players and coaches as well as sports managers, fans or spectators, even the football organizers themselves [6] or sports media [2].

The most important aspect of refereeing is the decision making process. Throughout the match, a referee must make the right decision quickly. Until now, only two studies have examined the veracity of referee's decisions and assistant referees [7], for example, counting the number of correct and wrong decisions related to game rules during the 1986 World Cup in Mexico. They found that of all the decisions made in 16 matches, $17 \%$ were incorrect (range 11-35\%). That it is very difficult to achieve implementation without errors from game law, errors have also been shown recently by Oudejans et al. to judge offside by the assistant referee [8]. In particular, they point out that the assistant referee's observation point relative to the offside line is an important determinant of the wrong decision in judging offside.

Of the many factors, there are three important factors that must be possessed by football referees, namely psychological factors (dealing with stress, mentality, and aggression), physiology (moving $10 \mathrm{~km}$ in a match) and professional (making accurate decisions and controlling the game) [9]. Many psychological mechanisms have been shown to reduce stress and anxiety related to performance such as self-efficacy [10].

A referee in leading a match needs excellent physical abilities, they must always move to get the ideal position, so that each event will be clearly visible and can decide on events based on what is seen, not based on responses from other things. Football referees in a match must move around 10-12 $\mathrm{km}$ with $10-15 \%$ physical activity at high speed, while for assistant referees move around 6-7 km with $15-20 \%$ high speed [11].

A referee when leading a match is assisted by two assistant referees who have duties as assistant referees in any event not seen by the referee, in particular is to see or detect offside positions carried out by attackers in accordance with the rules of game article 11 in the FIFA rule of the game (2016/2017). 
The assistant referee in detecting the attacking player in an offside position must move following the last second defending player during the match [11]. In addition to following the last second defending player, the assistant referee must also be able to predict who gave the attacker the bait, where the ball was played, in what situation the ball is played and where the attacker's position before the ball is played, from these positions an assistant referee must have an ideal view point [12].

Football games in Indonesia are increasingly developing, starting from the concept of playing to the vision and mission of playing, this can be seen from the form of the game that is fare for every team that competes especially in League 1 . The growing concept of play requires a referee to always learn and practice to always follow it, including the assistant referee. The assistant referee has a task that is arguably very heavy because it must always be aligned with the last second defensive player so that in offside decision making can be very clear and confident [8]. From this it indicates that the physical ability of an assistant referee has a big contribution in making decisions for assistant football referees. So in this study to determine the relationship of the assistant referee's physical abilities to offside decision making.

\section{METHOD}

The method used in this research is descriptive method. The population in this study were all FIFA Indonesia referees, totalling 7 assistants aged over 30 years under 35 . The sample in this study was taken using a total sampling technique, which is that the entire population was sampled and served in the Indonesian League 1 in 2017.

In data retrieval carried out when the referee assistant served in League 1. In data collection researchers used two forms, namely physical fitness test with YOYO and observations from match videos for decision making. The instrument used is the decision making of the referee in making decisions while the assistant referee is only decision-making article 11, which is about offside [13]. Analysis of the data used is correlation using the ANOVA test.

\section{RESULTS AND DISCUSSION}

\section{A. Results}

After the data from the sample is known, then the writer analyzes the data obtained. The results of testing and data analysis are calculated to get the average value and standard deviation. The results of decision-making and physical abilities of referees in Indonesian League 1 are as follows.

TABLE I. RESUlts OF CALCUlation of AVERAgE VAluE

One-Sample Statistics

\begin{tabular}{|l|l|l|l|}
\hline & Mean & Std. Deviation & \multicolumn{1}{|c|}{$\begin{array}{c}\text { Std. Error } \\
\text { Mean }\end{array}$} \\
\hline Physical ability & 45,5671 &, 01113 &, 00421 \\
\hline Decision-making & 7,0000 & 2,23607 &, 84515 \\
\hline
\end{tabular}

After the data is known, then the test is carried out using a spss to determine the effect of physical abilities on referee assistant offside decision making in Indonesian League 1, and the following results are obtained :

TABLE II. $\quad$ ANOVA $^{\mathrm{B}}$

\begin{tabular}{|c|c|c|c|c|c|c|}
\hline \multicolumn{2}{|c|}{ Model } & $\begin{array}{c}\text { Sum of } \\
\text { Squares }\end{array}$ & df & $\begin{array}{c}\text { Mean } \\
\text { Square }\end{array}$ & $\mathbf{F}$ & Sig. \\
\hline \multirow[t]{3}{*}{1} & Regression & 135 & 1 & 135 & 023 & $887^{a}$ \\
\hline & Residual & 29,865 & 5 & 5,973 & & \\
\hline & Total & 30,000 & 6 & & & \\
\hline
\end{tabular}

From these results it can be seen that there is a very meaningful relationship between physical abilities and assistant referees' offside decision making in the Indonesian League 1 with a score of 0.887 .

\section{B. Discussion}

From the calculation of the data it can be seen that the assistant referee in giving a decision in the field is influenced by adequate physical abilities, how can an assistant referee be equal to the second last player if he doesn't have good physical abilities.

Physical condition. This first aspect is an obligation for a referee and assistant referee before they will be on duty. They must pass a physical test before the competition takes place, if they do not pass a physical test they are not allowed to lead a match. In the Indonesian league, every referee who will be involved in the competition must take referee referee conducted by PSSI, every referee must take part in the activity if he wishes to serve in the Indonesian League 1. The function of physical ability itself in the performance of the referee is that the referee must always move through the game and strive to always be close to the event so that the decision given will be accurate, besides that the referee and assistant referee must always move in a match following the match and are asked not far from the incident [14]. For assistant referees in the case of offside determination, the referee assistant must have a good point of view between equals with the player holding the second last, follow where the ball will be played, where the attacker's initial position will touch the ball and where the ball will be played [15].

An assistant referee in his duty must always focus on the last second player with a period of low physical activity because it is adjusted to the one that occurs in the field, but the movements that the assistant referee has to do are walking, jogging, and sideways [16], a referee moves more in jogging, running, and sprinting compared to assistant referees so the Fédération Internationale de Football Association (FIFA) apply different requirements in terms of tests for either the referee or assistant referee [14]. Because of the high demands of soccer matches, a high level of physical fitness can help referees to ensure optimal positioning in making important decisions [17].

Important decisions that must be decided by an assistant referee regarding offside must be in accordance with the rules and understanding of offside itself, according to FIFA Article 
11 in the law of the games it is said that the player is in an offside position if it is closer to the opponent's goal line and second player last than ball, and parts of the head, body and legs except the hands. A player who is equal to the player holding the second last, the last two opponents or on the half of the game is not in an offside position. Referees can punish a player in an offside position only if, when the ball touches or is played by one of their teammates the player, in the opinion of the referee, is involved in active play by interfering with the game, disturbing the opponent or making a profit by being in that position [13]

In the writer's observation of the position of the assistant referee often lagging behind or not parallel with the two players last last, even though the decision is correct, and the existence of assistant referees who are too hasty in deciding an event, even though those who will control the ball are players who are not in an offside position. This is a problem that must be corrected by the Indonesian football organization. In this research, there are three important positions that are often carried out by assistant referees in League 1 that occur in matches, while the three positions are left behind with the second last player, the position is parallel to the last second player, and the position precedes the second last player. These three positions are often carried out, although sometimes decisions about offside are true, but the belief in a decision made becomes a question.

Understanding the rules of the game is a must for a referee, how a referee will decide a problem if he does not master the applicable regulations. Football regulations every year there are always changes, so referees and referee assistants must always be updated on the latest regulations. Regarding this understanding, not only the referee must master, but the coach, the player, the audience must master and recognize the rules that apply, so that there will be mutual respect between professions. A study states that understanding the rules of playing players, coaches, spectators, media and components related to football is very low [18].

Apart from these other things that can be of concern are experience factors. The experience factor itself can determine and influence the performance of the referee in the field [19], in Indonesia the discourse of limiting the age of referees to under 40 years is a problem that must be considered, because the experience factor itself is an important factor that must be considered. Though the level of maturity of football referees even reached the level of his career is at the age of more than 40 years [20].

\section{CONCLUSION}

From the results of this study it can be concluded that physical ability has a very significant influence on the decision of the assistant referee, especially in deciding the offside situation of players, certainly not only the influence of physical abilities, but there are other supporting factors which must be further investigated in future studies, such as as well as psychology, audience disruption, as well as understanding the rules of the game possessed by assistant referees.

\section{REFERENCES}

[1] R. Giulianotti and R. Robetson, Globalization and Football. London: Sage Publications, 2002

[2] F. Guillen, "La psicología del arbitraje y del juicio deportivo [The psychology of refereeing and judging in sports]," in Deporte y Psicología, eds. E. Garcés de los Fayos, A. Olmedilla, and P. Jara (Murcia: Diego Marín), pp. 667-684, 2006.

[3] P. Catteeuw, W. Helsen, B. Gilis, and J. Wagemans, "Decision-making skills, role specificity, and deliberate practice in association football refereeing," Journal of Sports Sciences, vol. 27, pp. 1125-1136, 2009.

[4] C. Tuero, B. Tabernero, S. Marquez, and F. Guillen, "Análisis de los factores que influyen en la práctica del arbitraje [Analysis of the factors affecting the practice of refereeing]," Sociedade Capixaba de Psicologia do Esporte, vol. 1, pp. 7-16, 2002

[5] K.J. Anderson and D.A. Pierce, "Officiating bias: the effect of fou differential on foul calls in NCAA basketball," J. Sports Sci., vol. 27, pp. 687-694, 2009.

[6] D.W. Rainey, "Sources of stress among baseball and softball umpires," Journal of Applied Sport Psychology, vol. 7, pp. 1-10, 1995.

[7] R. Van Meerbeek, D. Van Gool, and J. Bollens, Analysis of the refereeing decisions during the world soccer championship in 1986 in Mexico. In T. Reilly, A. Less, K. Davids \& W.J. Murphy (Eds.), Science and Football (pp. 377-392). London: E \& F.N. Spon, 1987.

[8] R.R.D. Oudejans, R. Verheijen, F.C. Bakker, J.C. Gerrits, M. Streinbru“ ckner, and P.J. Beek, "Errors in judging "offside" in football," Nature, vol. 404, pp. 33, 2000

[9] S. Wolfson and N. Neave, "Coping under pressure: Cognitive strategies for maintaining confidence among soccer referees," Journal of Sport Behavior, vol. 30, pp. 232-247, 2007.

[10] A. Bandura, Self efficacy: the exercise of control. New York: Freeman, 1997.

[11] J. Mallo, P. Gonzalez Frutos, D. Ju'arez, and E. Navarro, "Effect of positioning on the accuracy of decision-making of association footbal top-class referees and assistant referees during competitive matches," Journal of Sports Sciences, vol. 30, pp. 1437-1445, 2012

[12] P. Catteeuw, W. Helsen, B. Gilis, J.M. Garcia-Aranda, F. Tresaco, and J. Wagemans, "Offside decision making in the 2002 and 2006 FIFA World Cups," Journal of Sports Sciences.

[13] Fe'de' ration Internationale de Football Association (2016/2017), Laws of the game and universal guide for referees. Zurich: FIFA, 2017.

[14] J. Mallo, E. Navarro, J.M. Garc'1a-Aranda, and W. Helsen, “Activity profile of top-class association football referees in relation to fitness-tes performance and match standard," Journal of Sports Sciences, vol. 27, pp. 9-17, 2009.

[15] P. Catteeuw, B. Gilis, J. Wagemans, and W. Helsen, "Offside decision making of assistant referees in the English Premier League: Impact of physical and perceptual-cognitive factors on match performance," Journal of Sports Sciences, vol. 28, pp. 471-481, 2010.

[16] P. Krustrup, W. Helsen, M.B. Randers, J.F. Christensen, C. MacDonald A.N. Rebelo, et al. "Activity profile and physical demands of football referees and assistant referees in international games," J Sports Sci, vol. 27 , pp. 1167-76, 2009

[17] M. Weston, C. Castagna, F.M. Impellizzeri, M. Bizzini, A.M. Williams and W. Gregson, "Science and medicine applied to soccer refereeing an update," Sports Med, vol. 42, pp. 615-31, 2012.

[18] B. Gilis, W. Helsen, P. Catteeuw, E. Van Roie, and J. Wagemans, "Interpretation and application of the offside law by expert assistant referees: Perception of spatial positions in complex dynamic events on and off the field," Journal of Sports Sciences, vol. 27, pp. 551-563, 2009.

[19] C. Castagna, G. Abt, and S. D’Ottavio, “Competitive level differ- ences in Yo-Yo intermittent recovery and twelve minute run test performance in soccer referees," J Strength Cond Res, vol. 19, pp. 805-9.

[20] C. Castagna, G. Abt, S. D’Ottavio, and M. Weston, “Age-related effects on fitness performance in elite level soccer referees," J Strength Cond Res, vol. 19, pp. 785-90, 2005. 